\title{
Profile of Neurosurgical Patients in a Tertiary Level Intensive Care Unit in Nepal
}

\author{
Subhash Prasad Acharya, ${ }^{1}$ Binita Bhattarai, ${ }^{1}$ Adheesh Bhattarai, ${ }^{1}$ Saurabh Pradhan, ${ }^{1}$ Mohan Raj Sharma ${ }^{1}$ \\ ${ }^{1}$ Institute of Medicine, Tribhuvan University, Maharajgunj, Kathmandu, Nepal.
}

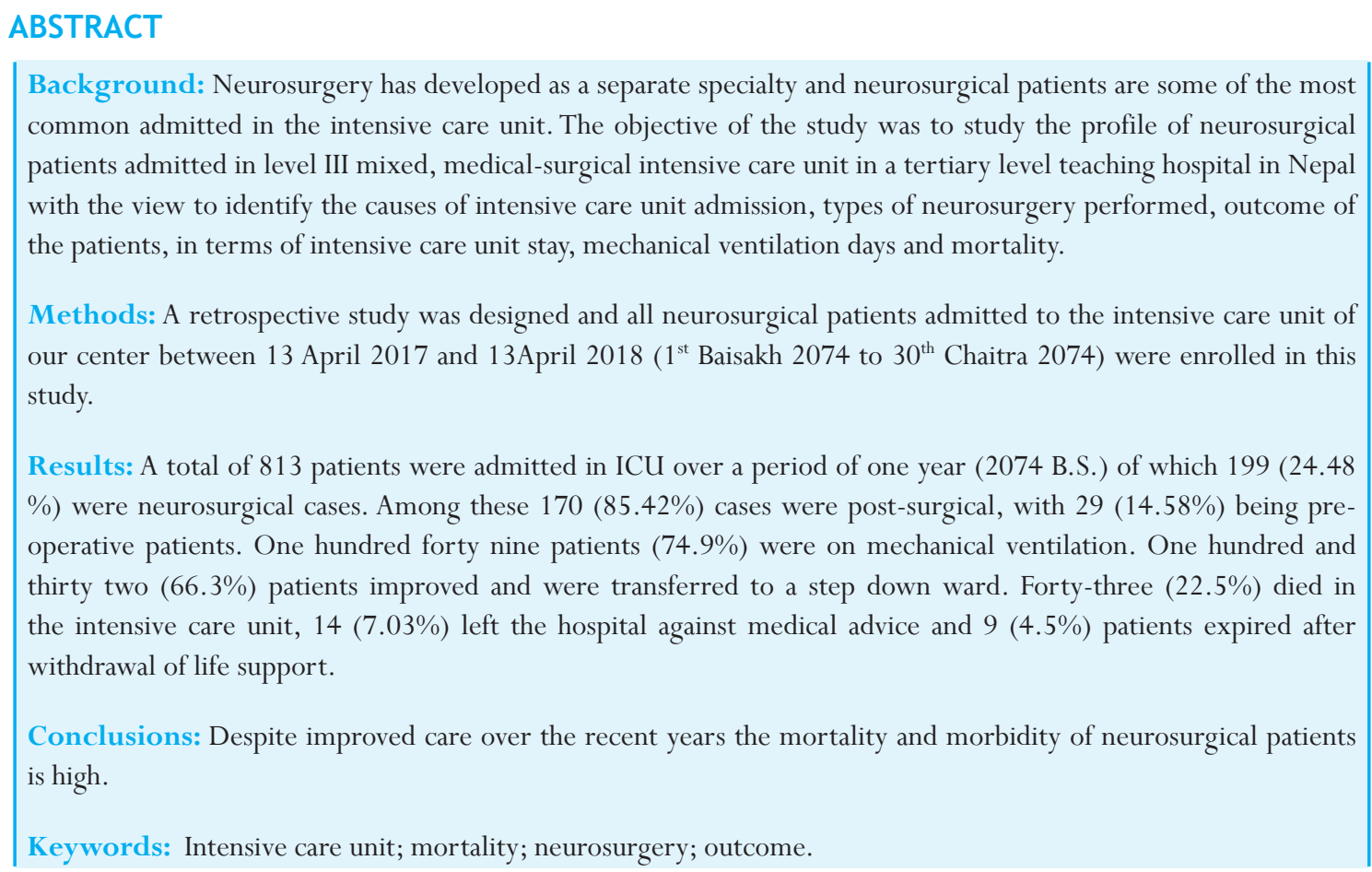

\section{INTRODUCTION}

Intensive Care Unit (ICU) admits most critically ill patients in hospital and Neurocritical care plays a vital role managing patients with primarily neurological disease, whether managed conservatively or surgically. ${ }^{1}$ The success of any neurosurgical intervention doesn't solely depend upon the operative procedure but also relies on appropriate postoperative critical care and involvement and contribution of multidisciplinary team. ${ }^{2}$

The eleven-bedded level III mixed medical-surgical ICU at Tribhuvan University Teaching Hospital (TUTH ICU) is semi-closed, managed by Department of Anesthesiology that admits all critical neurosurgical patients. Even though Neurosurgery was started in 1995 at TUTH, Neurosurgery specialty program $(M C h)$ started recently but Neurocritical care in Nepal is in its initial stages. ${ }^{3-6}$ There is limited data from Nepal regarding types and outcomes of neurosurgical patients in ICU. Thus this study was conducted with an objective that the findings will be helpful for implementation of strategies that would help decrease mortality and morbidity of neurosurgical patients in ICU and improve overall outcome. ${ }^{6}$

\section{METHODS}

After ethical approval from Institutional Review Committee of our institute, a retrospective study was conducted. All patients with neurosurgical problems admitted in the ICU over a period of one year from 13 April 2017 to 13 April 2018 (1 $1^{\text {st }}$ Baisakh 2074 to 30 Chaitra 2074) were included in the study. The data was obtained by review of ICU admission discharge book and electronic medical record and patient charts. The variables studied were age, sex, diagnosis, pre- or postoperative status; length of stay in ICU length of stay in mechanical ventilation, outcome (survivor, nonsurvivor, those leaving against medical advice) and readmission to ICU. The data were entered in Microsoft Excel and analyzed using SPSS.
DOI: http://dx.doi.org/10.3126/ jnhrc.v16i3.21434
Correspondence: Subhash Prasad Acharya, Institute of Medicine, Tribhuvan University, Maharajguni, Kathmandu, Nepal. Email: drsuvash@gmail.com, Phone: +9779851147242 . 


\section{RESULTS}

During the one-year study period, a total of 813 patients were admitted in the ICU of which 199 (24.48\%) were neurosurgical patients. Among them 105 (51.78\%) were male and 94 (48.22\%) were females. One hundred and seventy (85.42\%) patients were admitted for postoperative management, which included both elective and emergency surgeries and 29 (14.58\%) were admitted for other neurosurgical causes. Age wise distribution showed patients aged between 15 and 65 years to be the most common at 171 (85.42\%). Nine (4.52\%) patients aged below 15 years, while 19 (10.05\%) were aged more than 65 years (Figure 1).

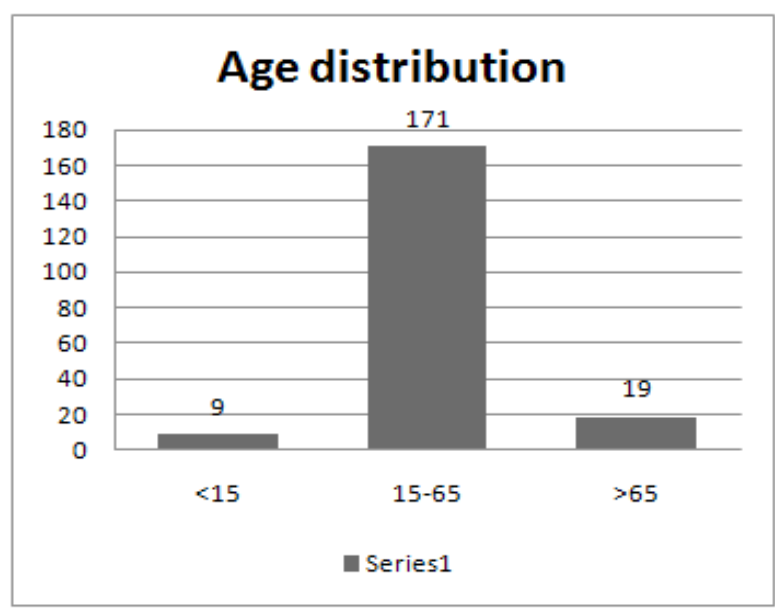

Figure 1. Age distribution (x-axis: Age in Years; $y$-axis: Number).

\begin{tabular}{lrr}
\hline Table 1. Types of neurosurgical patients in ICU. \\
\hline Diagnosis & Number & Percentage \\
\hline Aneurysm & 49 & 25 \\
\hline SDH & 13 & 7 \\
\hline EDH & 7 & 4 \\
\hline Hematoma & 5 & 3 \\
\hline Hemorrhage & 7 & 4 \\
\hline Hydrocephalus & 7 & 4 \\
\hline Tumors & 63 & 32 \\
\hline Infarction & 4 & 2 \\
\hline Spinal Injury & 14 & 7 \\
\hline Spinal Conditions & 4 & 2 \\
\hline DAl & 12 & 6 \\
\hline Venous Thrombosis & 2 & 1 \\
\hline AVM & 2 & 1 \\
\hline Abscess & 4 & 2 \\
\hline Metabolic & 2 & 1 \\
\hline Traumatic SAH & 4 & 2 \\
\hline & &
\end{tabular}

AVM: arteriovenous malformation, DAl: Diffuse axonal injury; EDH: extradural hemorrhage; SAH: subarachnoid hemorrhage; SDH: subdural hemorrhage

A total 149 patients who were mechanically ventilated (74.87\%) (Figure 2). The average length of mechanical ventilation was 4.7 days. There were only 11 patients with stroke, 7 hemorrhagic and 4 ischemic stroke, which required neurosurgical intervention and got admitted to our ICU.

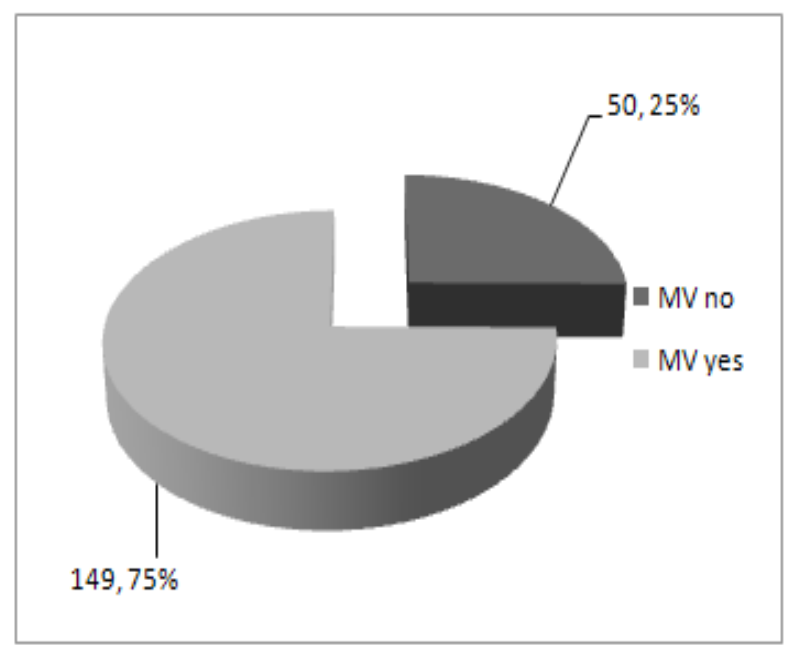

\section{Figure 2. Mechanical Ventilation (MV).}

One hundred and thirty two $(66.33 \%)$ patients improved and were transferred to a step down ward, 43 (21.6\%) died in the ICU, 14 (7.03\%) left the hospital against medical advice (LAMA) and 9 (4.5\%) patients expired after withdrawal of life support. Length of stay in the ICU and related mortality is shown in table 1.

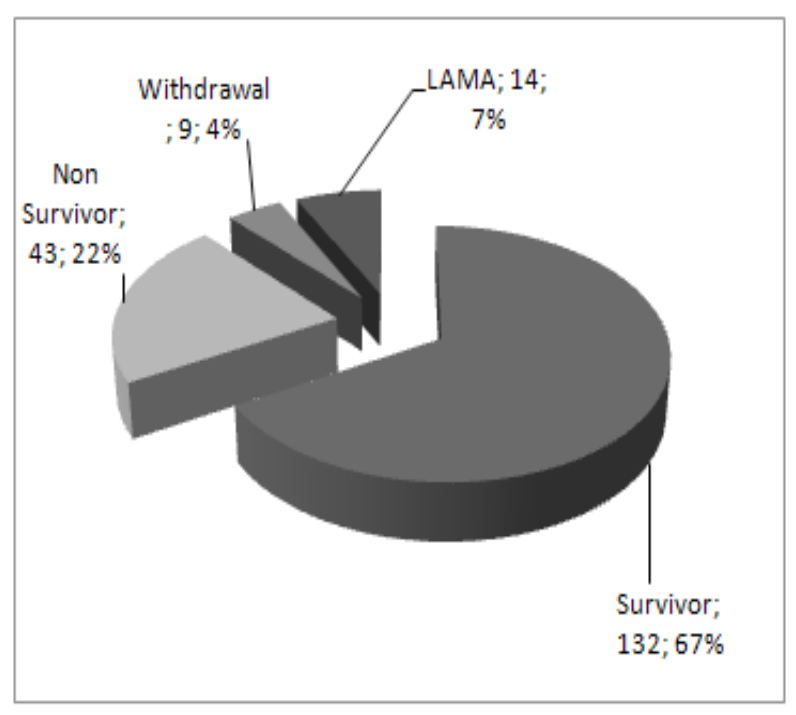

Figure 3. Outcome of neurosurgical patients. 
Table 2. Length of stay and associated mortality.

\begin{tabular}{lrrr}
$\begin{array}{l}\text { Length of ICU } \\
\text { stay }\end{array}$ & $\begin{array}{r}\text { Number of } \\
\text { patients }\end{array}$ & $\begin{array}{r}\text { Number of } \\
\text { deaths }\end{array}$ & Percentage \\
\hline 1 day & 46 & 10 & $21.7 \%$ \\
\hline 2 days & 40 & 5 & $12.5 \%$ \\
\hline 3 days & 23 & 7 & $30.4 \%$ \\
\hline 4 days & 23 & 6 & $26.0 \%$ \\
\hline $5-10$ days & 41 & 8 & $19.5 \%$ \\
\hline 10 days & 26 & 7 & $26.9 \%$ \\
\hline
\end{tabular}

The average length of stay in ICU (LOS ICU) was found to be 5.6 days whereas the average length of stay in mechanical ventilator (LOS MV) was found to be 4.7 days. The average length of stay on mechanical ventilation is shown in following figure 3. Maximum number of deaths occurred on the day of admission with 10 (23.2\%). Majority of the patients were transferred to step down wards within the first two days of admission, while 26 (13.1\%) patients were admitted in the ICU for more than 10 days. A total of 11 (5.52\%) patients underwent tracheostomy due to prolonged mechanical ventilation.

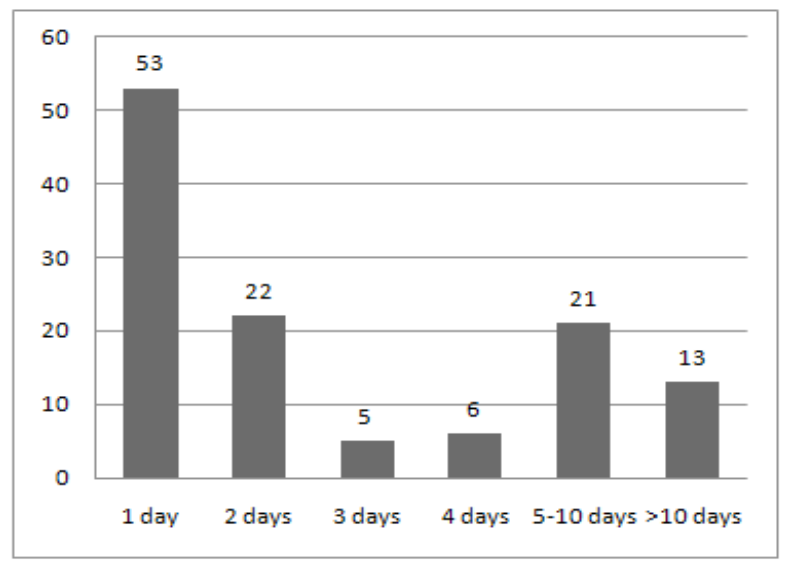

Figure 4. Length of Stay on Mechanical Ventilation (LOS MV).

Out of the 11 patients with stroke that required Neurosurgical intervention and admitted to ICU, only 2 patient with hemorrhagic stroke expired and one patient had tracheostomy and rest 9 patients got discharged out of ICU to step down unit.

There were a total of 14 readmissions with 4 patients being readmitted to the ICU within 48 hours of transfer to a step down unit and 10 cases after 48 hours of being transferred out.

All these patients were followed out of hospital and none of them have any death outside ICU in the hospital till hospital discharge.

\section{DISCUSSION}

Neurosurgical intensive care has evolved into a separate subspecialty all over the world however this concept although old is still at infancy in the developing world. This subspecialty has evolved from neurosurgical units treating postoperative cases to units that provide comprehensive medical and specialized neurological support for patients with life-threatening neurological diseases. Neurocritical care involves close collaboration and teamwork between Critical Care, Neurology, neurosurgery and this is a must to give the best management of these complex critical patients. The increasing role of the neurointensivists in these neurocritical care units has been associated with reduced hospital mortality and resource utilization. ${ }^{7,8}$

In Nepal, there are many studies and publications in Neurosurgery, and many articles from the neurosurgical ICU from other countries but there is only one article from Nepal regarding Neurosurgical ICU. 6, 9-12 The delay in development of Neurosurgical services and neurocritical care in Nepal can be due to various reasons that include financial constraints, lack of government regulations, poor medical control over the private institutions and lack of proper training of the hospital management and staff. $^{3-6}$

In our study, the male and female distribution was similar and most of them were admitted for postoperative management, including emergency and elective surgeries, which is similar to other studies by Roka et al and also similar to other ICU in low resource countries. ${ }^{6,13}$

Considering the stroke patients, there were only 11 patients who required neurosurgical intervention and further ICU management and the mortality was higher in patients admitted to ICU and more in hemorrhagic stroke than in ischemic stroke which was similar to study by Fanshawe et al. ${ }^{14}$

In a study by Nouira et al, when comparing ICU patients from Tunisia $(n=430)$ and France $(n=534)$, the patients were younger the mortality was lower in the French ICU and economical constraints was one reason that could explain differences in ICU performances. ${ }^{15}$

This retrospective study is just a profile of neurosurgical patients and did not include many parameters to compare with other studies. But the outcome and length of stay of these neurosurgical patients in this ICU is comparable to various other studies from Nepal, Nigeria and Singapore. ${ }^{6,15,16}$

This study is also comparable to another study from Austria on severe head injury where the mortality was $31.7 \%$, which also showed that there were no significant 
correlations between mechanisms of injury and severity of trauma, nor between mechanisms and ICU outcome. ${ }^{17,18}$

\section{CONCLUSIONS}

Neurosurgical outcomes are similar to other developed countries and ICUs that caters Neurosurgical patients are very limited in Nepal. Thus, along with advancement in development of Neurosurgical subspecialties, it is now time to develop Neurocritical care as a separate specialty.

\section{REFERENCES}

1. Sharma MR. Critical Care in Neurosurgery in Developing Countries. Journal of Institute of Medicine, 2013; 35(2): 92-100.

2. Mukesh M Gupta. Intensive care management of postoperative neurosurgical patients. In: Narendra Rungta, Rajesh Pande, Manish Munjal, Sudhir Khunteta, editors. Critical Care. JP Medical Ltd; 2015 Chapter 40; p. 346353.

3. Acharya SP. Critical care medicine in Nepal: where are we? International Health, 2013; 5 (2): 92-95,[DOI]

4. Mukhida K, Shilpakar SK, Sharma MR, Bagan M. Neurosurgery at Tribhuvan University Teaching Hospital, Nepal. Neurosurgery. 2005; 57(1): 172-80; [DOI]

5. Agrawal A, Kumar A, Agrawal CS, Pratap A. One year of neurosurgery in the eastern region of Nepal. Surgical neurology. 2008;69(6):652-6.[Science Direct] [DOI]

6. Roka YB, Ahmad SW, Shrestha M, Chaudhary A, Puri PR, Adhikari HB, et. al. Neurosurgical intensive care. Postgraduate Medical Journal of NAMS; 2010:10; 2; 6265.

7. Meena AK, Prasad VS, Murthy JM. Neurological intensive care in India--disease spectrum and outcome. Neurol India. 2001; 49 Suppl 1:S1-7. [Link]

8. Rincon F, Mayer SA. Neurocritical care: a distinct discipline? Curr Opin Crit Care. 2007; 13:115-21.[Link]

9. Suarez JI, Zaidat OO, Suri MF, Feen ES, Lynch G, Hickman J, et. al. Length of stay and mortality in neurocritically ill patients: impact of a specialized neurocritical care team. Crit Care Med. 2004; 32:2311-7.[Link]
10. Kumwilaisak K, Kyokong O, Indrambarya T. Factors influencing length of stay in neurosurgical intensive care unit. J Med Assoc Thai. 2008; 91:875-81. [Link]

11. Singh M, Vaishya S, Gupta S, Mehta VS. Economics of head injuries. Neurol India. 2006; 54:78-80.[Full Text]

12. Shrestha GS, Goffi A, Aryal D. Delivering neurocritical care in resource-challenged environments. Curr Opin Crit Care. 2016;22:100-5[DOI]

13. FA Onyekwulu, SU Anya. Pattern of admission and outcome of patients admitted into the Intensive Care Unit of University of Nigeria Teaching Hospital Enugu: A 5 year review. Nigerian J Clin Pract. 2015; 18, 6; 775-779.[Full Text Link]

14. Fanshawe M, Venkatesh B, Boots RJ. Outcome of stroke patients admitted to intensive care: experience from an Australian teaching hospital. Anaesth Intensive Care. 2002;30(5):628-32.[Full Text]

15. Nouira S, Roupie E, El Atrouss S, Durand-Zaleski I, Brun-Buisson C, Lemaire F, et al. Intensive care use in a developing country: a comparison between a Tunisian and a French unit. Intensive Care Med. 1998;24(11):1144-51. [Full Text]

16. Tan WT, Choy JM, Foo JM. A 5-year profile of trauma admissions to the surgical intensive care unit of a tertiary hospital in Singapore. Ann Acad Med Singapore. 2010; 39:363-7.[Full Text]

17. Rosso A, Brazinova A, Janciak I, Wilbacher I, Rusnak M, Mauritz W, et. al. Severe traumatic brain injury in Austria II: epidemiology of hospital admissions. Wien Klin Wochenschr. 2007; 119:29-34.[Full Text]

18. Mauritz W, Wilbacher I, Majdan M, Leitgeb J, Janciak I, Brazinova A, et. al. Epidemiology, treatment and outcome of patients after severe traumatic brain injury in European regions with different economic status. Eur J Pub Health. 2008; 18, 6, 575-580.[DOI][Full Text] 